J. Dairy Sci. 92:3402-3410

doi:10.3168/jds.2008-1229

(c) American Dairy Science Association, 2009.

\title{
Heritability estimates associated with alternative definitions of mastitis and correlations with somatic cell score and yield
}

\author{
J. E. Vallimont, ${ }^{*}$ C. D. Dechow, ${ }^{* 1}$ C. G. Sattler, $†$ and J. S. Claył \\ *Department of Dairy and Animal Science, The Pennsylvania State University, University Park 16802 \\ †Select Sires Inc., Plain City, OH 43064 \\ fDairy Records Management Systems, Raleigh, NC 27603
}

\section{ABSTRACT}

The objectives of this study were to compare alternative mastitis definitions and to estimate genetic correlations of producer-recorded mastitis with somatic cell score (SCS) and yield. Cow health events and lactation records from June 2002 through October 2007 were provided by Dairy Records Management Systems (Raleigh, NC). First- through fifth-lactation records from cows calving between 20 and 120 mo of age and that calved in a herd-year with at least $1 \%$ of cows with a clinical mastitis event were retained. The edited data contained 118,516 lactation records and 1,072,741 testday records of 64,893 cows. Mastitis occurrence $(1=$ at least one mastitis event during lactation or test-day interval, $0=$ no mastitis events), number of mastitis events during lactation, SCS, and yield were analyzed with animal models (single trait) or sire-maternal grandsire models (multiple trait) in ASREML. Comparisons were made among models assuming a normal distribution, a binary distribution, or Poisson distribution (for total episodes). The overall incidence of clinical mastitis was $15.4 \%$; and heritability estimates ranged from $0.73 \%$ (test-day interval mastitis with a linear model) to $11.07 \%$ (number of mastitis episodes with a Poisson model). Increased mastitis incidence was genetically correlated with higher SCS (range 0.66 to 0.88 ) and was generally correlated with higher yield (range -0.03 to 0.40 ), particularly during first lactation (0.04 to 0.40). Significant genetic variation exists for clinical mastitis; and health events recorded by producers could be used to generate genetic evaluations for cow health. Sires ranked similarly for daughter mastitis susceptibility regardless of how mastitis was defined; however, test-day interval mastitis and a total count of mastitis episodes per lactation allow a higher proportion of mastitis treatments to be included in the genetic analysis.

Received April 3, 2008.

Accepted March 9, 2009.

${ }^{1}$ Corresponding author: cdechow@psu.edu
Key words: mastitis, heritability, threshold model, alternative measures

\section{INTRODUCTION}

In spite of advancements in antibiotic therapies along with refined milking protocols and management techniques, mastitis remains a costly disease for dairy farms and milk processors nationwide. In 2006, $14.3 \%$ of herd test-days had SCC $>500,000$ cells $/ \mathrm{mL}$ among herds using DHI and testing for SCC (Miller et al., 2007). Quantity and quality of cheese produced from high SCC milk are compromised (Munro et al., 1984; Politis and Ng-Kwai-Hang, 1988), and shelf life of refrigerated fluid milk is shorter for high SCC milk than for low SCC milk (Ma et al., 2000). On the farm, costs associated with mastitis include the value of milk production lost to an intramammary infection, treatment costs, and culling (Shim et al., 2004).

Genetic selection for increased milk yield has been successful and opportunities to select for healthier cows with improved longevity are increasing. Predicted transmitting abilities for SCS and productive life have been published by the USDA Animal Improvement Programs Laboratory since 1994 (Shook, 2001). Somatic cell counts are commonly converted to SCS for genetic evaluations, and a strong genetic correlation between SCS and clinical mastitis has been established by Rogers et al. (1998) and Heringstad et al. (2006b). Previous studies have demonstrated that mastitis is a heritable trait with heritabilities ranging from 0.01 to as high as 0.42 (e.g., Pösö and Mäntysaari, 1996; Nash et al., 2000), with most studies reporting heritabilities $<0.10$ (e.g., Carlén et al., 2004; Zwald et al., 2004). Heritability estimates for mastitis are sensitive to the underlying model assumptions, with estimates from a linear model reported to be much smaller (0.03) than estimates from a threshold model (0.07 to 0.08) using the same data (Heringstad et al., 2003b; 2006a). Most frequently, data from national health recording systems in Scandinavian countries have been used for health-related genetics studies. Heringstad et al. (2007) 
Table 1. Mastitis abbreviations created by producers and recorded in PCDART dairy management software (Dairy Records Management Systems, Raleigh, NC)

Mastitis abbreviations

\begin{tabular}{ll}
\hline ALLM & MSPE \\
AMFL & NSTA \\
AMFR & PIRS \\
AMLR & PRSU \\
AMOX & RFRR \\
AMRR & SA \\
CEF & SCLM \\
CMST & SPCM \\
CMT+ & SPDC \\
CNOS & SPEC \\
COLI & SPFL \\
ECOL & SPFR \\
FREM & SPLR \\
GENT & SPRR \\
GR- & TIAY \\
GR+ & TIFL \\
IVMA & TIFR \\
M4QT & TILR \\
MAST & TIRR \\
MCEF & TODY \\
MLFQ & TOXC \\
MLRQ & TOXI \\
MRFQ & TXM \\
MRRQ & \\
\hline
\end{tabular}

demonstrated through a long-term selection study that selection against clinical mastitis could improve mastitis resistance. Multiple studies (Zwald et al., 2004, 2006; Abdel-Azim et al., 2005) have used producer-recorded data in mastitis analyses. Results from the Zwald et al. (2004) study provide support for accurate genetic analyses using producer-recorded health data.

Mastitis is a broad term that refers to an inflammation of the mammary tissue; however, in terms of quantitative genetic analyses of lactation records, "mastitis" can be defined in several ways. Very often, mastitis is considered as a binary trait, diseased or not diseased, across an entire lactation (Zwald et al., 2004; Heringstad et al., 2006b). The total number of mastitis episodes during an entire lactation can be considered for genetic analyses (Heringstad et al., 2006a; RodriguesMotta et al., 2007). The window of time during which a cow could be diseased or not can be narrowed to the time interval between 2 test-days, in which a cow would have as many mastitis designations as test-day intervals (Hinrichs et al., 2005). Heringstad et al. (2003a) utilized a similar approach with mastitis defined in 30-d increments, whereas Zwald et al. (2006) split parities 1 through 3 into 4 lactation segments.

The criteria by which producers record mastitis may be more varied than the methods used for analysis. Although many herds use software such as PCDART (Dairy Records Management Systems, Raleigh, NC) or Dairy Comp 305 (Valley Ag Software, Tulare, CA) to collect, summarize, and archive health data, a standardized system for recording health information is lacking in the United States. This makes genetic analysis of producer-recorded health data challenging because of the likely variation in ways that producers define health events. The absence of standardized health records in the United States has required that genetic selection for mastitis be through indirect means only (SCS and udder composite), which is not as efficient as direct selection based on clinical mastitis records. Ødegård et al. (2003) found that selection based on clinical mastitis records results in $43 \%$ more efficiency than indirect selection using SCS, although both methods did improve clinical mastitis rates in second-crop daughters.

The first objective of this study was to estimate the heritability of mastitis on the observed and underlying scales defined in 3 different ways: diseased or not for an entire lactation, the number of total episodes within a single lactation, and diseased or not during each testday interval. The second objective of the study was to estimate the genetic correlations of producer-recorded mastitis with SCS and milk, fat, and protein yields.

\section{MATERIALS AND METHODS}

\section{Data and Edits}

Dairy Records Management Systems (DRMS, Raleigh, NC) provided 640,420 lactation records from June 2002 to February 2008 for use in this study. Original data represented 334,335 cows from 806 progeny-test herds using PCDART in 39 states. Producer-recorded health records through October 2007 that were entered by herd managers in the PCDART dairy management software were also supplied by DRMS. The health data included herd and registration or ear-tag number for the cow, an up to 4-letter acronym for health events along with an expanded 12-letter description of the acronym, and the date of each health event. There is much variation among herds for acronyms used to represent mastitis in PCDART records, and an inclusive list of mastitis abbreviations used for this study is in Table 1. Lactation and health records were provided in 6 separate updates from DRMS.

Lactation records from Holstein cows calving between 20 and 120 mo of age with a unique and valid registration number, a recorded value for SCS, that had a first-lactation record available, and that were in fifth or earlier lactation were considered for analyses. Lactation and health records were merged and cow-lactations with no health data were assumed to represent a nondiseased lactation.

Mastitis was defined as 3 separate single traits. A whole-lactation approach was used (WL), in which cow 
lactation records having at least one mastitis event occurring between $10 \mathrm{~d}$ before calving and 365 DIM were assigned a 1 and those without were assigned a 0 . Herd data were retained if lactation incidence rate of $\mathrm{WL}$ was at least $1 \%$. The second mastitis trait examined mastitis in the interval between successive herd test dates (TI), with cows being assigned a 0 or 1 based on whether or not they had mastitis during a test-day interval. The first test-day interval was defined as $10 \mathrm{~d}$ before calving through first test-day. Subsequent testday intervals were defined as the day after previous test through the day of current test. The maximum length for a test period was limited to $90 \mathrm{~d}$ and the average length of test interval was $31.0 \pm 8.7 \mathrm{~d}$. Test-day intervals were chosen instead of fixed DIM intervals so that mastitis observations could be merged with subsequent test-day yield and SCS. The final mastitis trait examined the total number of unique episodes for each cowlactation (TN), with this value capped at 10 episodes per cow-lactation. Recorded mastitis treatments were considered to represent unique episodes if they occurred at least $7 \mathrm{~d}$ after the previously reported treatment. It was assumed that treatments occurring within $7 \mathrm{~d}$ of the initial episode often represent routine follow-up treatments, whereas those occurring later represented either a new infection or initial treatment failure.

Four calving seasons were used in the analyses: January through March, April through June, July through September, and October through December. A minimum of 5 cows per herd-year season or herd-test-day was required. Seasons were combined within herd-years if fewer than 5 cows were present. Not all herds had data for the entire period. Only 13 herds had data available for 2002, but 196 herds had data available for 2007 . Final data included 118,516 cow lactations from 64,893 cows from 230 herds and sired by 6,339 bulls with 2,139 herd-year-seasons of calving, 10,065 herd-test-days, and 1,072,741 test-day records. Fifty percent of cows had records from at least 2 lactations.

\section{Statistical Models}

Four types of models were used to evaluate the data: linear model, 2-trait linear model, threshold model (for WL and TI only), and Poisson model (for TN data only). The following single-trait animal model that assumed varying distributions for WL, TI, and TN was fit in ASREML (Gilmour et al., 2006):

$$
\begin{aligned}
y_{i j k l}= & \sum_{x=1}^{2} b_{a x} \times A g e^{X}\left(P G_{i}\right)+C G_{j} \\
& +W K_{k}+a_{l}+p_{l}+e_{i j k l},
\end{aligned}
$$

where $y=\mathrm{WL}$, TI, or TN (linear model), liability to WL or TI (threshold model), or a Poisson variable $(\mathrm{TN}) ; b_{a x}=$ linear and quadratic regression coefficients for age at calving nested within parity group $(P G) i$ (parity 1,2 , and $\geq 3$ ); $C G=$ contemporary group $j$, which was herd-year-season of calving for WL and TN and herd-test-date for TI; $W K=$ the fixed effect for week of lactation $k$, which was the week of lactation at the final test-date or at dry-off for WL and TN, or week of lactation on herd-test-date for TI; $a=$ the random effect of animal $l ; p=$ the permanent environmental effect of cow $l$; and $e=$ random error. A normal distribution was assumed for initial analysis of WL, TI, and TN. A second series of analyses assumed a binary distribution with a probit link function for WL and TI (threshold model) and a Poisson distribution for TN. Generalized linear mixed models are used in ASREML for analysis of traits with a non-normal distribution. For the Poisson distribution, the log-link between TN and a linear predictor of $\mathrm{TN}\left(\mathrm{TN}_{\mathrm{l}}\right)$ was $\log _{\mathrm{e}}\left(\mathrm{TN}_{\mathrm{l}}\right)$. The probit link used the inverse normal cumulative density function to associate WL and TI with linear predictors of WL and TI, respectively. Residual variance for the threshold and Poisson models were fixed at 1. Variance associated with CG was not considered when calculating heritability estimates for threshold and Poisson models.

Herd-year-season and herd-test-day were treated as fixed effects for linear models; however, CG was treated as a random effect to facilitate convergence due to the presence of CG with all zeroes or ones for threshold and Poisson models. Week of lactation was also replaced with regression on third (TI) or fourth (WL and TN) order polynomials for threshold and Poisson models to avoid convergence issues associated with any week of lactation that had no mastitis events. The WL data set had $15.4 \%$ of cows with a mastitis episode, and those cows had an average of 1.54 episodes in the TN data set. The TI analysis had a mastitis rate per test interval of $2.3 \%$.

The following 2-trait linear model with a sire-maternal grandsire pedigree was used to estimate genetic correlations between mastitis and SCS or yield:

$$
\mathbf{Y}=\mathbf{X} \boldsymbol{\beta}+\mathbf{Z} \mathbf{a}+\mathbf{W} \mathbf{p}+\mathbf{e}
$$

where $\mathbf{Y}=$ a vector of SCS, milk yield, fat yield, or protein yield and either WL, TI, or TN; $\boldsymbol{\beta}=$ a vector of fixed effects; $\mathbf{a}=$ a vector of random pedigree effects; $\mathbf{p}=$ a vector of permanent environmental effects; $\mathbf{e}=$ a vector of residual errors; $\mathbf{X}, \mathbf{Z}$, and $\mathbf{W}$ are the corresponding incidence matrices. Somatic cell score was either lactation-average SCS for WL and TN, or test- 
day SCS for TI. Mature-equivalent yield was analyzed with WL and TN, and test-day yield was analyzed with TI. A fixed effect was included for the interaction of the number of SCS used to generate lactation-average SCS and availability of SCS on first test date (for those herds who measure SCS every other month). All other fixed effects were as defined for single-trait analysis (equation 1). The pedigree file included 138,118 total animals for the single-trait analysis. For the bivariate analyses, there were 64,893 cows with records, 6,339 sires, 2,708 maternal grand-sires that were not also sires, and 191 paternal ancestors for a total pedigree size of 74,141 individuals.

Sire PTA for WL, TN, and TI on the observed scale (PTAWL $_{\mathrm{O}}$, PTATN $_{\mathrm{O}}$, and PTATI $_{\mathrm{O}}$, respectively) and underlying scale $\left(\mathbf{P T A W L} \mathbf{L}_{\mathrm{U}}, \mathbf{P T A T N}_{\mathrm{U}}\right.$, and PTATI $_{U}$, respectively) were obtained from ASREML output files. Reliabilities for sire PTA were calculated as $1-\mathrm{PEV} / \sigma_{a}^{2}$, where PEV is the squared standard error for the mastitis $\mathrm{EBV}$ and $\sigma_{a}^{2}$ is the additive genetic variance. Standard errors for EBV are available directly from ASREML output.

Additional analyses were performed to determine the effect of data edits and model assumptions. The repeatability model used to analyze all lactation data assumes that mastitis in first lactation is genetically identical to mastitis in later lactations and that mastitis is the same trait in all test-day intervals. Heritabilities and genetic correlations were therefore estimated separately for first-lactation cows to determine if genetic parameters varied between first and later lactations. A total of $69.9 \%$ of cows in the study were sired by proven bulls, which could bias estimates because their sires represented a select group. Therefore, an additional analysis of $32,270 \mathrm{WL}$ and TN records and 280,905 TI records from 19,537 cows sired by 3,042 bulls with one or more progeny test daughters was conducted to determine the extent of bias introduced through sire selection. Both first-lactation and progeny-test records were analyzed with linear models.

\section{RESULTS AND DISCUSSION}

Descriptive statistics for WL, TI, TN, yields, and SCS are reported in Table 2. The average lactation length across all lactations was $348 \mathrm{~d}$, and $77 \%$ of cows had lactations of at least $270 \mathrm{~d}$ before data cut offs. Mastitis incidence was greater than $20 \%$ for lactations 3 through 5 and lowest for lactation 1 (12.2\%). Average SCS increased with successive lactations, whereas average mature-equivalent yields were highest in second lactation. For those cows with mastitis, the average number of mastitis episodes ranged from 1.39 in lactation 1 to 1.72 in lactation 3 . The percentage of cows with no mastitis events was $84.6 \%, 10.8 \%$ had 1 mastitis event, $2.7 \%$ had 2 mastitis events, and $1.8 \%$ had 3 or more mastitis events. The proportion of testday intervals with mastitis was highest in lactation 4 $(3.53 \%)$ and lowest in lactation $1(1.71 \%)$. The average DIM for mastitis ranged from 97 in lactation 4 to 112 in lactation 2; however, median DIM ranged from 67 to 86 , indicating that DIM was right skewed.

The distribution of mastitis events by DIM is shown in Figure 1. Twenty-seven percent of mastitis events occurred from -10 through 10 DIM. Mastitis incidence and average test-day milk, fat, and protein yields and SCS in 30-d increments are reported in Table 3 for records used to analyze TI mastitis. Not all cows had their first test within $30 \mathrm{~d}$ of calving, so the total number of observations between 1 and 30 DIM $(106,661)$ was less than that between 31 and 60 DIM $(109,697)$ and 61 and 90 DIM $(108,213)$. Average test-day milk yield was highest between 61 and 90 DIM (40.30 kg), whereas fat yield tended to peak earlier (between 31 and 90 DIM) than protein yield (between 91 and 150 DIM). Somatic cell scores declined from calving until 90 DIM and then increased through the remainder of lactation. Mastitis was most frequent during the first 30 DIM.

The current data support that mastitis as recorded by producers is a heritable trait. Heritability estimates for all data using linear models ranged from 0.73 to $3.82 \%$ and were lower than estimates from the underlying scale, which ranged from 4.98 to $11.07 \%$ (Table 4 ). Standard error estimates were also larger for estimates from the underlying scale. Defining mastitis as a TN trait resulted in the highest heritability estimates on both scales, whereas heritability estimates for the TI trait were lowest within each analysis. Genetic parameter estimates from linear models indicated a $5.9 \%$ genetic standard deviation for WL, a $1.3 \%$ genetic standard deviation for TI, and 0.126 incidences for TN.

Heritability and genetic standard deviation estimates were less when only first-lactation records were considered, which was expected because of the lower mastitis incidence rate in first lactation combined with a linear model analysis. Conversely, heritability and genetic standard deviations were higher when data from only daughters of sires with progeny test daughters were considered, particularly for TN. The estimates indicate that heritability and genetic variance may have been biased downward somewhat because of a large proportion of cows from proven sires that had no first-crop daughters available.

Although heritability estimates were lowest for TI, the larger number of observations resulted in reliability estimates that were higher for TI than for WL and $\mathrm{TN}$. The average reliability of $\mathrm{PTATI}_{\mathrm{O}}$ for bulls with 


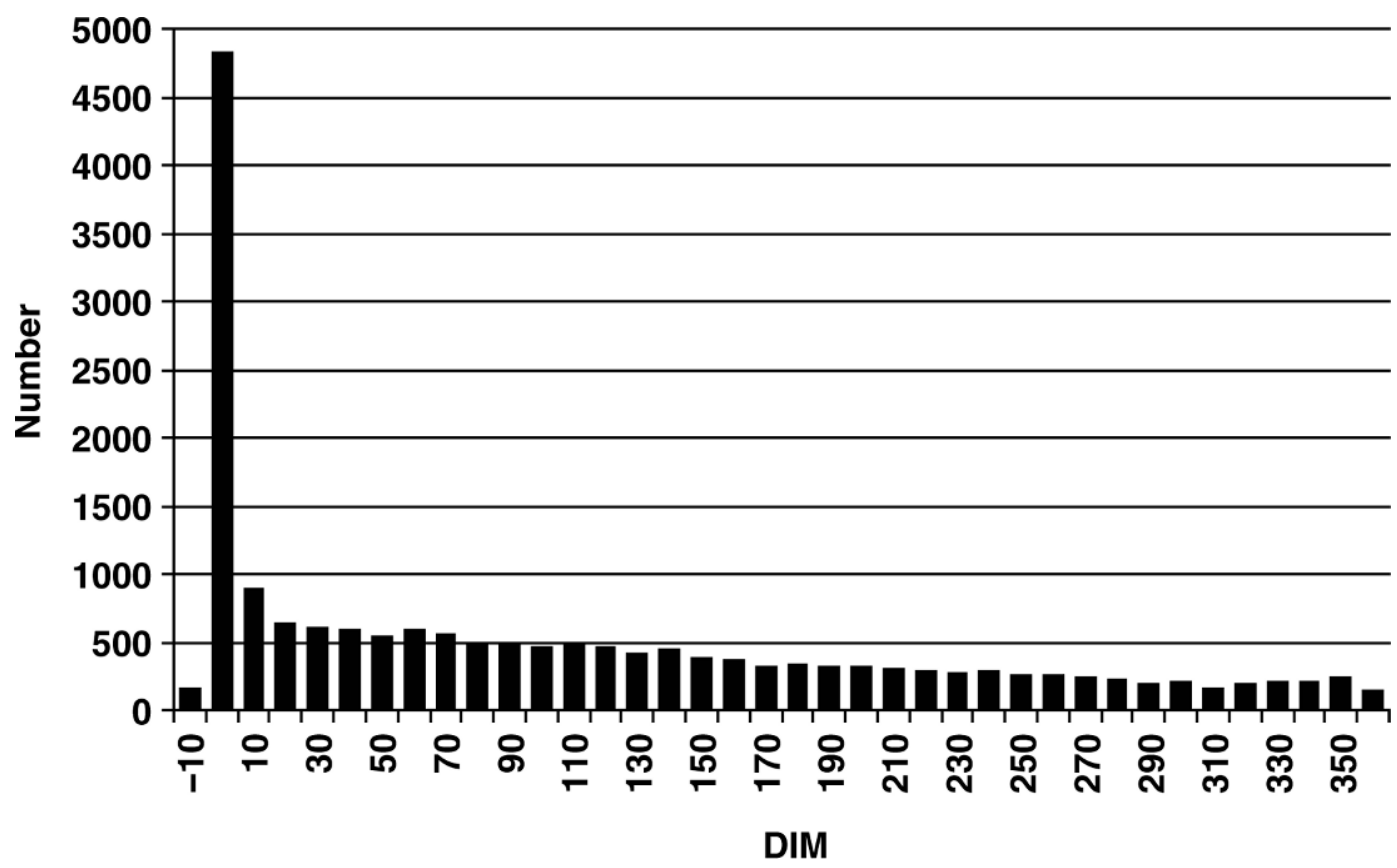

Figure 1. Distribution of first mastitis episode from -10 to 365 DIM in 10-d increments for producer-recorded mastitis events used to estimate the heritability of mastitis.

between 25 and 150 daughters was 0.56 compared with 0.49 for $\mathrm{PTAWL}_{\mathrm{O}}$ and 0.53 for $\mathrm{PTATN}_{\mathrm{O}}$. Likewise, average reliability for $\operatorname{PTATI}_{\mathrm{U}}(0.54)$ was higher than PTAWL $_{\mathrm{U}}(0.47)$ or $\mathrm{PTATN}_{\mathrm{U}}(0.46)$ for the same subset of sires. Heritability estimates were higher for threshold and Poisson models, but reliabilities were higher for PTA from linear models. This observation is in agreement with a simulation by Carlén et al. (2006) that reported true accuracies corresponding more closely to heritability estimates from a linear model compared with heritability estimates from a threshold model.

The distribution of TN appeared to be zero-inflated (84.6\% zeros). Rodrigues-Motta et al. (2007) compared zero-inflated Poisson models with a standard Poisson model to analyze TN in Norwegian Red cattle using Bayesian analysis. In their analysis, $76 \%$ of cows had no mastitis incidence and the zero-inflated model was favored by a posterior-predictive model test, but not by a

Table 2. Characteristics of final data used in the genetic analysis of producer-recorded mastitis records

\begin{tabular}{|c|c|c|c|c|c|}
\hline Item & \multicolumn{5}{|c|}{ Lactation } \\
\hline Total lactations, n & 64,893 & 32,170 & 13,870 & 5,541 & 2,042 \\
\hline $\mathrm{WL}^{1}$ incidence rate, $\%$ & 12.2 & 17.6 & 21.6 & 22.5 & 21.9 \\
\hline Mean $\mathrm{TN}^{1,2}$ & 1.39 & 1.61 & 1.72 & 1.69 & 1.63 \\
\hline $\mathrm{TI}^{1}$ incidence rate, $\%$ & 1.71 & 2.66 & 3.46 & 3.53 & 3.45 \\
\hline Mean lactation DIM & 357 & 342 & 331 & 324 & 320 \\
\hline SD of lactation DIM & 121 & 112 & 115 & 117 & 136 \\
\hline Lactations <270 DIM, \% & 19.7 & 26.0 & 30.0 & 31.6 & 34.4 \\
\hline Age at calving, mo & 25 & 39 & 52 & 65 & 78 \\
\hline Mean mature-equivalent milk, $\mathrm{kg}$ & $11,996.5$ & $12,208.4$ & $11,593.6$ & $11,157.4$ & $10,847.5$ \\
\hline Mean mature-equivalent fat, kg & 429.3 & 433.9 & 417.5 & 401.8 & 389.7 \\
\hline Mean mature-equivalent protein, $\mathrm{kg}$ & 348.9 & 356.9 & 340.5 & 326.9 & 316.4 \\
\hline
\end{tabular}

${ }^{1} \mathrm{WL}=$ presence $(1)$ or absence $(0)$ of mastitis from -10 to $365 \mathrm{~d}$ in milk; TN $=$ total number of mastitis episodes from -10 to $365 \mathrm{~d}$ in milk; $\mathrm{TI}=$ presence (1) or absence (0) of mastitis during test-day intervals.

${ }^{2}$ Mean TN was calculated only for cows with at least 1 mastitis episode. 
Table 3. The number of observations (n), average test-day milk yield, fat yield, protein yield, and SCS, and the percentage of cows with mastitis during test-day intervals in 30-d increments

\begin{tabular}{lcccccc}
\hline DIM & $\mathrm{n}$ & Milk, kg & Fat, kg & Protein, kg & SCS & Mastitis, $\%$ \\
\hline $1-30$ & 106,661 & 33.31 & 1.39 & 1.02 & 2.85 & 4.47 \\
$31-60$ & 109,697 & 39.26 & 1.40 & 1.09 & 2.30 & 2.67 \\
$61-90$ & 108,213 & 40.30 & 1.40 & 1.13 & 2.25 & 2.04 \\
$91-120$ & 104,613 & 40.21 & 1.38 & 1.15 & 2.34 & 2.06 \\
$121-150$ & 100,349 & 39.30 & 1.36 & 1.15 & 2.41 & 2.10 \\
$151-180$ & 95,437 & 38.18 & 1.33 & 1.14 & 2.50 & 2.03 \\
$181-210$ & 91,624 & 36.82 & 1.30 & 1.11 & 2.58 & 1.99 \\
$211-240$ & 81,423 & 35.10 & 1.26 & 1.08 & 2.68 & 1.94 \\
$241-270$ & 80,898 & 33.23 & 1.21 & 1.04 & 2.79 & 1.91 \\
$271-300$ & 79,893 & 31.31 & 1.16 & 0.99 & 2.92 & 2.01 \\
$301-330$ & 62,672 & 30.08 & 1.13 & 0.97 & 3.05 & 1.83 \\
$331-365$ & 51,815 & 29.00 & 1.10 & 0.95 & 3.17 & 1.74 \\
\hline
\end{tabular}

residual analysis. The rank correlation of sires was also reported to be 0.98 , indicating small differences when a zero-inflated Poisson model was fit. The relatively high percentage of cows with no mastitis in this and other studies suggests that zero-inflated models may warrant further development.

When all data were considered, repeatability estimates ranged from 3.12 to $11.58 \%$ on the observed scale (Table 4). Repeatability estimates were significantly higher on the underlying scale for TI (10.82 vs. 3.12\%) and TN (40.71 vs. $11.58 \%$ ). No problems with model convergence were encountered in the current study in spite of the inclusion of multiple random effects and the use of an animal model; however, the repeatability estimate for $\mathrm{TN}$ was higher than expected. The reason for high repeatability with TN is not clear. It is possible that cows treated for mastitis remain highly susceptible throughout life. Herd managers may also check cows with a history of mastitis more rigorously, which would increase the likelihood of mastitis detection in such cows and inflate permanent environment effects. High repeatability estimates for test-day interval mastitis have been reported previously (Hinrichs et al., 2005).

The heritability estimates from the analyses on the observed scale are similar to those from both Hansen et al. (2002) and Carlén et al. (2004) whose heritability estimates ranged from 1.0 to $3.5 \%$ using mixed linear models. Abdel-Azim et al. (2005) reported a mastitis heritability estimate of $16 \%$ for cows in all lactations, and Zwald et al. (2006) estimated heritability to be $9 \%$ for first-lactation cows; both of these studies used producer-recorded mastitis data and a threshold model to analyze mastitis as a WL trait. Heringstad et al. (2003b) reported a heritability estimate of $6.6 \%$ when first-lactation WL data were analyzed using a threshold model, and the heritability for number of mastitis episodes in first lactation was reported to be $8 \%$ using an ordered threshold model (Heringstad et al., 2006a). A study in the United Kingdom using cows in first through fifth lactations reported a heritability of $3.4 \%$ using a threshold model and WL data (Kadarmideen and Pryce, 2001). In contrast to the current study, no

Table 4. Heritability $\left(\mathrm{h}^{2}\right)$ and repeatability $(\mathrm{r})$ with their respective standard errors $(\mathrm{SE})$, and genetic standard deviation $\left(\mathrm{SD}_{\mathrm{a}}\right)$ estimates for mastitis ${ }^{1}$ using all lactation records and on the observed and underlying ${ }^{2}$ scales, all lactation records from cows sired by bulls with first-crop daughters available on the observed scale, and first-lactation records on the observed scale

\begin{tabular}{|c|c|c|c|c|c|c|c|}
\hline Trait & Model & Data & $\mathrm{h}^{2}, \%$ & $\mathrm{SE}$ & $\mathrm{r}, \%$ & $\mathrm{SE}$ & $\mathrm{SD}_{\mathrm{a}}$ \\
\hline $\mathrm{TN}$ & Linear & All lactations & 3.82 & 0.005 & 11.58 & 0.004 & 0.126 \\
\hline $\mathrm{TI}$ & Linear & All lactations & 0.73 & 0.001 & 3.12 & 0.001 & 0.013 \\
\hline $\mathrm{TN}$ & Poisson & All lactations & 11.07 & 0.014 & 40.71 & 0.005 & 0.432 \\
\hline TI & Threshold & All lactations & 4.98 & 0.005 & 10.82 & 0.003 & 0.236 \\
\hline WL & Linear & First crop available & 3.33 & 0.010 & 10.51 & 0.008 & 0.059 \\
\hline WL & Linear & First lactation & 1.72 & 0.004 & - & - & 0.040 \\
\hline $\mathrm{TN}$ & Linear & First lactation & 1.64 & 0.004 & - & - & 0.067 \\
\hline TI & Linear & First lactation & 0.35 & 0.001 & 3.86 & 0.001 & 0.008 \\
\hline
\end{tabular}

${ }^{1} \mathrm{WL}=$ presence $(1)$ or absence $(0)$ of mastitis from -10 to $365 \mathrm{~d}$ in milk; TN $=$ total number of mastitis episodes from -10 to $365 \mathrm{~d}$ in milk; $\mathrm{TI}=$ presence (1) or absence (0) of mastitis during test-day intervals.

${ }^{2}$ WL and TI were analyzed with a threshold model, whereas the underlying scale for TN was a Poisson distribution. 
Table 5. Correlations of PTA for daughter mastitis ${ }^{1}$ generated from the observed and underlying ${ }^{2}$ scales (diagonal), correlations among PTA of different mastitis definitions generated on the observed scale (above diagonal), and correlations among PTA of different mastitis definitions generated on the underlying scale (below diagonal) for 221 sires with 50 or more daughters

\begin{tabular}{llll}
\hline & WL & TN & TI \\
\hline WL & 0.95 & 0.88 & 0.90 \\
TN & 0.95 & 0.88 & 0.93 \\
TI & 0.93 & 0.95 & 0.92 \\
\hline
\end{tabular}

${ }^{1} \mathrm{WL}=$ presence $(1)$ or absence $(0)$ of mastitis from -10 to $365 \mathrm{~d}$ in milk; $\mathrm{TN}=$ total number of mastitis episodes from -10 to $365 \mathrm{~d}$ in milk; TI $=$ presence (1) or absence (0) of mastitis during test-day intervals.

${ }^{2} \mathrm{WL}$ and TI were analyzed with a threshold model, whereas the underlying scale for TN was a Poisson distribution.

differences in heritability estimates between WL and TN traits were found by Lund et al. (1999). A testday interval model in the Hinrichs et al. (2005) study resulted in a heritability estimate for mastitis of $6 \%$ using a threshold model for test intervals occurring from calving to 300 DIM, which was higher than the $4.98 \%$ estimated by the current study for test-interval mastitis. Heringstad et al. (2003a) used a longitudinal analysis of mastitis occurrence in 30-d increments and reported daily heritability estimates that were generally in the range of 5 to $10 \%$, although estimates increased at both ends of the lactation.

Correlations among PTA for WL, TN, and TI on the observed and underlying scales are reported in Table 5 for 221 sires with at least 50 daughters. The correlation between $\mathrm{PTAWL}_{\mathrm{O}}$ and $\mathrm{PTAWL}_{\mathrm{U}}$ was 0.95 , whereas the correlation between $\mathrm{PTATI}_{\mathrm{O}}$ and $\mathrm{PTATI}_{\mathrm{U}}$ was 0.92 . The correlation was not as high between PTATN $_{O}$ and PTATN $_{U}$ (0.88), which may indicate that TN was more sensitive to model assumptions than WL or TI. Additionally, correlations among PTA for WL, TN, and TI were higher when estimated on the underlying scale (range 0.93 to 0.95$)$ than on the observed scale (0.88 to
0.93). Correlations on both the observed and underlying scales were higher between TN and TI compared with those involving WL.

Table 6 contains information about estimated genetic and permanent environmental correlations between mastitis and SCS, milk yield, fat yield, and protein yield. Genetic correlations between mastitis and SCS were $0.69,0.66$, and 0.75 for $\mathrm{WL}, \mathrm{TN}$, and TI, respectively, and are similar to the correlation of 0.70 reported by Kadarmideen and Pryce (2001). Genetic correlations based on first-lactation records only were generally stronger (range 0.79 to 0.88 ). These results support conclusions from other studies that mastitis and SCS are not interchangeable measures of udder health (Hinrichs et al., 2005; Heringstad et al., 2006b), particularly after first lactation; however, selection for reduced SCS has been proven to result in improved resistance to mastitis (Ødegård et al., 2003). Permanent environmental correlations between mastitis and SCS for WL and TN were both 0.42 , whereas the estimate for TI was 0.54 .

The relationship between herd-average mastitis incidence rate during test intervals and herd-average test-day SCS was not strong, in spite of the strong genetic correlation between mastitis incidence and SCS (Figure 2). A comparable relationship was illustrated in a review by Schukken et al. (2003). It is expected that herd-average SCS will increase as the incidence rate for mastitis rises; however, the correlation between herd-average TI incidence rate and herd-average testday SCS was only 0.24 . The correlation between TI and SCS was 0.18 when TI and SCS were not averaged across test-days for each herd. This would support the hypothesis that there is wide variation in the accuracy and completeness of mastitis recording across herds. Herds with a high average SCS and an apparent low frequency of mastitis likely have poor mastitis detection protocols and have a very high subclinical mastitis rate. Herds with low average SCS and high mastitis

Table 6. Genetic $\left(r_{\mathrm{g}}\right)$ and permanent environmental $\left(\mathrm{r}_{\mathrm{pe}}\right)$ correlations of mastitis ${ }^{1}$ with SCS, milk yield, fat yield, and protein yield for all lactations and first lactation

\begin{tabular}{|c|c|c|c|c|c|c|c|c|c|}
\hline Item & \multicolumn{3}{|c|}{ All lactations $\mathrm{r}_{\mathrm{g}}{ }^{2}$} & \multicolumn{3}{|c|}{ All lactations $\mathrm{r}_{\mathrm{pe}}{ }^{3}$} & \multicolumn{3}{|c|}{ First lactation $r_{g}{ }^{4}$} \\
\hline SCS & 0.69 & 0.66 & 0.75 & 0.42 & 0.42 & 0.54 & 0.88 & 0.79 & 0.82 \\
\hline Fat & 0.11 & 0.12 & -0.03 & -0.18 & -0.20 & -0.17 & 0.14 & 0.13 & 0.04 \\
\hline Protein & 0.32 & 0.27 & 0.09 & -0.21 & -0.21 & -0.20 & 0.36 & 0.40 & 0.35 \\
\hline
\end{tabular}

${ }^{1} \mathrm{WL}=$ presence $(1)$ or absence $(0)$ of mastitis from -10 to $365 \mathrm{~d}$ in milk; $\mathrm{TN}=$ total number of mastitis episodes from -10 to $365 \mathrm{~d}$ in milk; $\mathrm{TI}=$ presence $(1)$ or absence $(0)$ of mastitis during test-day intervals.

${ }^{2} \mathrm{SE}$ for $\mathrm{r}_{\mathrm{g}}$ range from 0.052 to 0.078 .

${ }^{3} \mathrm{SE}$ for $\mathrm{r}_{\mathrm{pe}}$ range from 0.019 to 0.051 .

${ }^{4} \mathrm{SE}$ for $\mathrm{r}_{\mathrm{g}}$ range from 0.072 to 0.133 . 


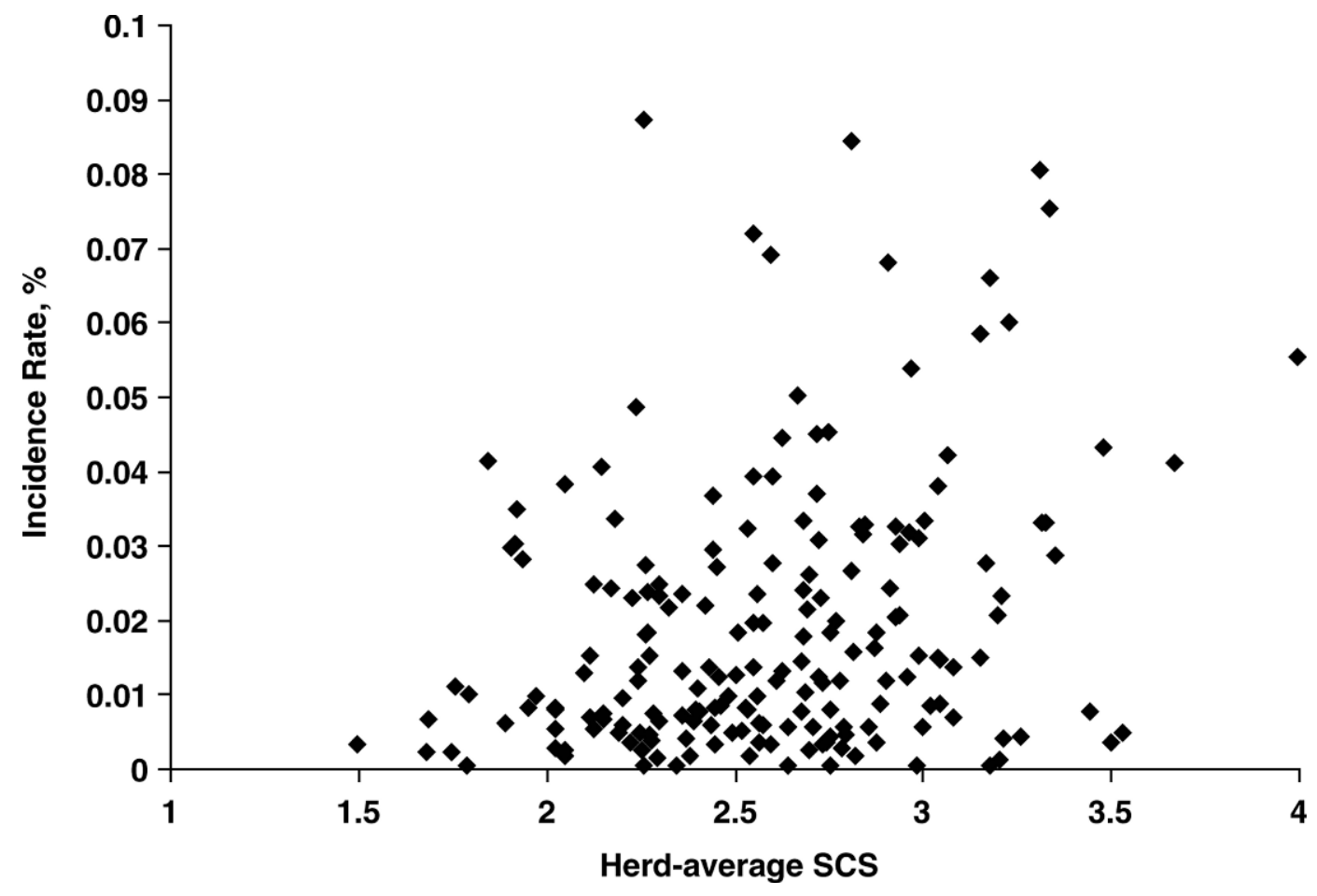

Figure 2. Relationship between herd-average SCS on test-day and herd test-interval mastitis incidence rate.

frequency likely have a relatively lower incidence of subclinical mastitis and perhaps a high rate of false positives. It is clear that relying on recorded herd mastitis incidence rates to determine the prevalence of mastitis within a herd and to determine the effectiveness of a herd's mastitis management program will often lead to inaccurate conclusions. In spite of this, comparing mastitis incidence rates with herd-average SCS could be a useful measure to determine how effectively mastitis is diagnosed in a herd and may help identify progeny test herds with more accurate mastitis recording.

Genetic correlations between mastitis and yield traits ranged from -0.03 to 0.32 when all lactations were considered, but were more unfavorable (range 0.04 to 0.40 ) when only first lactation was considered (Table 6 ). Genetic correlations between mastitis and fat yield were generally less unfavorable than genetic correlations of mastitis with milk and protein yield. Carlén et al. (2004) reported genetic correlations between mastitis and fat yield that decreased from 0.22 to 0.01 for first through third lactations. Many other studies have reported higher correlations between mastitis and protein yield, with reported values ranging from 0.19 to 0.43 (Lund et al., 1999; Carlén et al., 2004; Hinrichs et al., 2005). Permanent environmental correlations between mastitis and production traits were all negative, ranging from -0.17 to -0.21 . The negative correlations likely reflect reduced future milk yield after a mastitis episode. These estimates differed from those of Uribe et al. (1995) whose permanent environmental correlations for production traits were all close to zero for firstlactation Canadian Holsteins.

The genetic parameters for mastitis and correlations of mastitis with yield and SCS assume that mastitis, yield, and SCS are the same traits within and across lactation. Others have reported genetic correlations between mastitis in different lactations that are significantly $<1$ (Zwald et al., 2006), and mastitis in different lactation stages has genetic correlations less than unity (Heringstad et al., 2003a). The genetic correlations presented here provide evidence of the general relationship of mastitis with yield and SCS. Those relationships likely vary depending on parity and stage of lactation and could be further explored with multiple-trait or random regression models. An advantage of TI over WL and TN is that mastitis could more easily be analyzed with models that account for genetic differences both within and across lactation.

\section{CONCLUSIONS}

Producer-recorded mastitis events are heritable and can be defined in multiple ways. A count of mastitis episodes or occurrence of mastitis during test-day intervals allowed the use of a larger proportion of available mastitis episodes compared with a whole-lactation ap- 
proach, and analysis of TI resulted in generally higher reliabilities for sire PTA than were observed for WL or TN. Analysis of mastitis in different lactation stages could be facilitated with TI, which had sire PTA that were strongly correlated with TN. Mastitis was unfavorably correlated with yield, particularly milk and protein yields, regardless of mastitis definition. Additionally, genetic correlations between mastitis and yield were more unfavorable in first lactation than in all lactations. Somatic cell score was strongly correlated with mastitis in all lactations (range 0.66 to 0.75 ), and was more strongly correlated with mastitis in first lactation (range 0.79 to 0.88 ).

\section{REFERENCES}

Abdel-Azim, G. A., A. E. Freeman, M. E. Kehrli Jr., S. C. Kelm, J. L. Burton, A. L. Kuck, and S. Schnell. 2005. Genetic basis and risk factors for infectious and noninfectious diseases in US Holsteins. I. Estimation of genetic parameters for single diseases and general health. J. Dairy Sci. 88:1199-1207.

Carlén, E., U. Emanuelson, and E. Strandberg. 2006. Genetic evaluation of mastitis in dairy cattle using linear models, threshold models, and survival analysis: A simulation study. J. Dairy Sci. 89:4049-4057.

Carlén, E., E. Strandberg, and A. Roth. 2004. Genetic parameters for clinical mastitis, somatic cell score, and production in the first three lactations of Swedish Holstein cows. J. Dairy Sci. 87:30623070.

Gilmour, A. R., B. J. Gogel, B. R. Cullis, S. J. Welham, and R. Thompson. 2006. ASREML User Guide. Release 2.0. VSN International Ltd., Hemel Hempstead, UK.

Hansen, M., M. S. Lund, M. K. Sørensen, and L. G. Christensen, 2002. Genetic parameters of dairy character, protein yield, clinical mastitis, and other diseases in the Danish Holstein cattle. J. Dairy Sci. 85:445-452.

Heringstad, B., Y. M. Chang, I. M. Andersen-Ranberg, and D. Gianola. 2006a. Genetic analysis of number of mastitis cases and number of services to conception using a censored threshold model. J. Dairy Sci. 89:4042-4048.

Heringstad, B., Y. M. Chang, D. Gianola, and G. Klemetsdal. 2003a. Genetic analysis of longitudinal trajectory of clinical mastitis in first-lactation Norwegian cattle. J. Dairy Sci. 86:2676-2683.

Heringstad, B., D. Gianola, Y. M. Chang, J. Ødegård, and G. Klemetsdal. 2006b. Genetic associations between clinical mastitis and somatic cell score in early first-lactation cows. J. Dairy Sci. 89:2236-2244

Heringstad, B., G. Klemetsdal, and T. Steine. 2007. Selection responses for disease resistance in two selection experiments with Norwegian red cows. J. Dairy Sci. 90:2419-2426.

Heringstad, B., R. Rekaya, D. Gianola, G. Klemetsdal, and K. A. Weigel. 2003b. Genetic change for clinical mastitis in Norwegian cattle: A threshold model analysis. J. Dairy Sci. 86:369-375.

Hinrichs, D., E. Stamer, W. Junge, and E. Kalm. 2005. Genetic analyses of mastitis data using animal threshold models and genetic correlation with production traits. J. Dairy Sci. 88:2260-2268.
Kadarmideen, H. N., and J. E. Pryce. 2001. Genetic and economic relationships between somatic cell count and clinical mastitis and their use in selection for mastitis resistance in dairy cattle. Anim. Sci. $73: 19-28$.

Lund, M. S., J. Jensen, and P. H. Petersen. 1999. Estimation of genetic and phenotypic parameters for clinical mastitis, somatic cell production deviance, and protein yield in dairy cattle using Gibbs sampling. J. Dairy Sci. 82:1045-1051.

Ma, Y., C. Ryan, D. M. Barbano, D. M. Galton, M. A. Rudan, and K. J. Boor. 2000. Effects of somatic cell count on quality and shelf-life of pasteurized fluid milk. J. Dairy Sci. 83:264-274.

Miller, R. H., H. D. Norman, and L. L. M. Thornton. 2007. Somatic cell counts of milk from Dairy Herd Improvement herds during 2006. USDA AIPL Research Report SCC8 (2-07). Beltsville, MD.

Munro, G. L., P. A. Grieve, and B. J. Kitchen. 1984. Effects of mastitis on milk yield, milk composition, processing properties and yield and quality of milk products. Aust. J. Dairy Technol. 39:7-16.

Nash, D. L., G. W. Rogers, J. B. Cooper, G. L. Hargrove, J. F. Keown, and L. B. Hansen. 2000. Heritability of clinical mastitis incidence and relationships with sire transmitting abilities for somatic cell score, udder type traits, productive life, and protein yield. J. Dairy Sci. 83:2350-2360.

Ødegård, J., G. Klemetsdal, and B. Heringstad. 2003. Genetic improvement of mastitis resistance: Validation of somatic cell score and clinical mastitis as selection criteria. J. Dairy Sci. 86:41294136

Politis, I., and K. F. Ng-Kwai-Hang. 1988. Association between somatic cell counts of milk and cheese yielding capacity. J. Dairy Sci. $71: 1720-1727$.

Pösö, J., and E. A. Mäntysaari. 1996. Relationships between clinical mastitis, somatic cell score, and production for the first three lactations of Finnish Ayrshire. J. Dairy Sci. 79:1284-1291.

Rodrigues-Motta, M., D. Gianola, B. Heringstad, G. J. M. Rosa, and Y. M. Chang. 2007. A zero-inflated Poisson model for genetic analysis of the number of mastitis cases in Norwegian Red cows. J. Dairy Sci. 90:5306-5315.

Rogers, G. W., G. Banos, U. Sander Nielsen, and J. Philipsson. 1998. Genetic correlations among somatic cell scores, productive life, and type traits from the United States and udder health measures from Denmark and Sweden. J. Dairy Sci. 81:1445-1453.

Schukken, Y. H., D. J. Wilson, F. Welcome, L. Garrison-Tikofsky, and R. N. Gonzalez. 2003. Monitoring udder health and milk quality using somatic cell counts. Vet. Res. 34:579-596.

Shim, E. H., R. D. Shanks, and D. E. Morin. 2004. Milk loss and treatment costs associated with two treatment protocols for clinical mastitis in dairy cows. J. Dairy Sci. 87:2702-2708.

Shook, G. 2001. Breeding selection and somatic cell counts: Where are we today? Pages 113-127 in Natl. Mastitis Counc. Reg. Mtg. Proc., Arlington, VA. Natl. Mastitis Counc., Inc., Madison, WI.

Uribe, H. A., B. W. Kennedy, S. W. Martin, and D. F. Kelton. 1995 Genetic parameters for common health disorders of Holstein cows. J. Dairy Sci. 78:421-430.

Zwald, N. R., K. A. Weigel, Y. M. Chang, R. D. Welper, and J. S. Clay. 2004. Genetic selection for health traits using producerrecorded data. I. Incidence rates, heritability estimates, and sire breeding values. J. Dairy Sci. 87:4287-4294.

Zwald, N. R., K. A. Weigel, Y. M. Chang, R. D. Welper, and J. S. Clay. 2006. Genetic analysis of clinical mastitis data from onfarm management software using threshold models. J. Dairy Sci. 89:330-336. 